\title{
Research on Tourism English Curriculum Reform Based on Cooperative Learning under the Background of Innovative Talents Cultivation
}

\author{
Yuan Kong \\ Jining Medical University \\ Jining, China
}

\author{
Ya Kong* \\ Qufu Normal University \\ Qufu, China
}

\begin{abstract}
Based on the analysis of the characteristics of tourism English course and under the guidance of cooperative learning theory, this paper explores the principles, steps and evaluation of cooperative learning in tourism English, changes the existing teaching mode, and makes a tentative exploration to improve the teaching effect of tourism English course and the comprehensive quality of students. On the basis of understanding, learning and mastering the basic theory of cooperative learning and the research results of relevant scholars, it makes a tentative analysis and research on the curriculum orientation, curriculum objectives and other related issues of tourism English in colleges and universities. According to the needs, it studies and analyses the conditions of cooperative learning in tourism English, and clarifies the relevant elements that should be paid attention to in cooperative learning. Then, it makes a gradual arrangement and exploration on how to carry out cooperative learning in tourism English. After the completion of this step, it is believed that the new teaching mode needs to be evaluated to assess whether it can be helpful for the use of the curriculum and the improvement of teaching level. Therefore, it attempts to further explore the evaluation system of cooperative learning, hoping to provide a reference evaluation system for tourism English curriculum, so as to promote the cultivation of innovative tourism English professionals in a real sense.
\end{abstract}

Keywords-tourism English; innovative talents; cooperative learning; curriculum reform

\section{INTRODUCTION}

The traditional English teaching model is on the basis of the teachers' teaching and students' passive acceptance. Teachers spend a lot of time and energy to teach students to memorize words, analyze sentences, explain grammar, and practice mechanically. There is no room for students to play freely. For a long time, college students have been excluded from English teaching, so they have no interest in English learning. Such a teaching model can not realize the linguistic value and function of English, especially professional English. In the field of quality training, it is impossible to improve students' initiative and integration. In this context, professional English teaching calls for the introduction and use of new teaching modes.

Cooperative learning is a learning mode and teaching

This paper is sponsored by the Industry-University Cooperative Project of Ministry of Education (Grant No. 201801200014); Scientific Research Support Fund for Teachers of Jining Medical University (Grant No. JYFC2018RW020); The Visiting Scholar Funded Program of Young Backbone Teachers in Jining Medical University

Corresponding author: Ya Kong, Email: kongy_1116@163.com method aiming at cultivating students' comprehensive ability, stimulating students' initiative in spontaneous learning, and making full use of the mechanism of collective work-sharing and self-learning. Cooperative learning, as a new teaching mode, is a supplement and promotion to traditional teaching. It is conducive to improving students' comprehensive ability, has been recognized by educators from all walks of life, and also has been praised in other courses. In their new book Educational Reform Research, Ellis and Fotz, the famous American educational critics, assert that "cooperative teaching is at least one of the largest educational reforms if it is not the largest one in the contemporary era." The introduction of cooperative teaching mode into tourism English curriculum can meet the needs of tourism English curriculum reform and the training of tourism English professionals.

\section{ANALYSIS OF TOURISM ENGLISH COURSE BASED ON COOPERATIVE LEARNING}

\section{A. The orientation of Tourism English Course}

Tourism English and hotel management are the application programs for tourism English and English majors. It is also a compulsory course for those engaged in the tourism service industry. This course is based on the industry and according to the needs of the industry, it is the backbone of professional foreign language ability improvement. It provides students with the basic knowledge, skills and innovative abilities needed to learn tourism English, as well as the basic skills of communication and communication with the outside world. It also trains students' practical ability to engage in foreignrelated tourism reception [1]. It also lays a good foundation for students to further study other professional English courses and engage in foreign-related tourism practice.

\section{B. Objectives of Tourism English Course}

Tourism English, as a compulsory course for tourism majors, aims to enable students to have a correct ethical and professional outlook on foreign-related tourism work by adopting task-driven, scenario simulation and industry practice, and to master the working process of six links in foreignrelated tourism activities: eating, living, traveling, shopping and entertainment, so as to become an industry practitioner who has fluent English ability and strong enthusiasm for tourism business posts. 


\section{Conditions for Implementing Cooperative Learning}

\section{1) Advanced teaching ideas}

Good teaching philosophy is a prerequisite for successful teaching. Cooperative teaching, as a kind of teaching method that we all agree with at present, is fundamentally an advanced teaching idea and conforms to the current direction and goal of quality education in our country [2].

The introduction of new teaching ideas is a new experience for both teachers and students. As far as teachers are concerned, whether the courses they teach are suitable for cooperative teaching and whether the teaching effect reflects the teaching objectives are also the worries of teachers after they change their teaching methods. How to solve all these specific problems and how to cooperate with schools will directly affect teachers' acceptance of new teaching ideas and methods and their later use effect. For students, the challenge is greater. The change of educational methods will inevitably change students' learning habits and thinking modes. In this process, students' level of acceptance and degree of cooperation after familiarity with the process are also the test of new teaching methods.

Therefore, how to effectively land and implement the new teaching concept is a key issue, and also an important factor affecting the smooth development of teaching.

\section{2) Cultivation of good cooperative awareness}

In contemporary society, the individual ability will appear very little in front of the systematic task. Whether to know how to help oneself accomplish the task with the help of other forces will be the greatest test for contemporary young people. The spirit of cooperation and the sense of cooperation have become one of the criteria for judging the comprehensive ability of people. Cooperative learning requires team members to have a certain sense of cooperation.

Cooperation requires the establishment of appropriate mutual understanding and trust. The traditional learning activity is a self-centered competitive learning activity, which lacks frequent and effective communication, interaction and cooperation between students. Teachers' teaching is also a oneway infusion of knowledge, which fails to effectively provide students with cooperative learning opportunities. Therefore, the congenital deficiency causes the lack of cooperative consciousness of modern students. Tourism English is a communication-oriented professional skill. It is necessary for students to cultivate a good sense of cooperation, which is also a prerequisite for cooperative teaching [3]

As an organizer of collective learning, teachers must be aware of cooperation and have a good sense of it, and the distance between teachers and students are very close. While students appreciate the kindness and care of teachers, they have the feelings of respecting teachers and believing in teachers, and establish a teacher-student relationship of mutual communication, mutual trust and cooperation to provide a warm and united learning atmosphere for students to cooperate.

At the same time, tourism English teachers can establish healthy working communication with other teachers, promote each other in teaching, and ensure the positive and upward state of the whole class.

\section{3) Cultivation of skillful communication skills}

Cooperation is based on trust and benefits from communication. Communication skills have become the most necessary talents for young people in contemporary society. Good communication will provide a high-quality guarantee for the completion of things, and communication skills need to be cultivated, which involves many aspects, not only to master communication skills, language use, but also to learn to observe people's speech and behavior, learn to control the personal emotion, learn to listen and so on. The conditions and endowments of each student are different, and the communication ability of each student is naturally different. The difference of ability will inevitably affect the overall effect of the whole cooperative group, but it is inevitable that this objective reality exists [4]. Therefore, on the one hand, cooperative teaching accommodates the existence of such students, on the other hand, it should create opportunities and conditions for them to improve their communication and expression ability, provide an environment for self-expression, and encourage them to actively exercise themselves and express themselves. Other members and teachers should be encouraged to avoid discrimination or non-cooperation.

The focus of cooperative learning is to cultivate students communication and treatment ability. Only by dealing with interpersonal relationships within groups can cooperative education be guaranteed. This skill is embodied in all aspects, such as when others put forward their opinions, they should be open-minded to accept, and give respect and praise. If there are differences, we should have the mentality to accommodate other's opinions, to control our emotions, and to achieve common ground while reserving differences. Interpersonal skills learning is not a one-step process, but a step-by-step process. Teachers should guide and emphasize the direction of disadvantaged students, and regularly share relevant knowledge and skills with them.

Language as a means of communication does not have any emotional color. However, when communicating and interacting, the speaker will adopt different language, tone and order of expression, which will lead to different communication effects and produce different or even opposite results. Therefore, how to use language will also be a great challenge to test students' communicative competence and the main content of learning. In fact, an increasing number of teachers need to develop cooperative learning. The task is more important and the observation is more meticulous. It is also a great challenge for teachers.

\section{IMPLEMENTATION OF COOPERATIVE LEARNING STEPS IN TOURISM ENGLISH}

\section{A. Course Task Determination}

Firstly, according to the syllabus and curriculum, teachers decompose and finalize in advance, and implement the main contents, key points, difficulties, main assessment ability objectives and cooperation tasks of this class. Secondly, according to the teaching task, teachers determine the specific task objectives that the curriculum requires students to complete. Task objectives need to be informed to students before teaching so that students can preview and understand in 
advance, so as to effectively prepare for the course. Furthermore, teachers decompose tasks according to cooperative goals. The division of labor should take into account the actual situation of the classroom and students. Task difficulty should be challenging, and ability training should be expanded. The objective requirement of the openness of tourism English is that the place or plot of its occurrence is uncontrollable, which requires students to have the ability to adapt to the circumstances [5].

\section{B. Classroom Implementation and Notices for Implementing Cooperative Learning of Tourism English}

Before the cooperative teaching, teachers should concentrate on teaching basic knowledge before class, arrange cooperative teaching tasks and group work according to the content to organize and mobilize. Although the task of each course is single, the role of the scene involved in each task is not fixed. Therefore, according to the principle of group setting, each group needs to be reorganized to achieve the effective integration of "two-level" organizations, to ensure that the division of tasks is in place, the specific duty is to a specific person and the role is clear. According to the teaching task, each group is arranged to carry out cooperative tasks. Teachers and team leaders are responsible for the effective implementation of the cooperative tasks of each group, and inspect the progress and effectiveness of related activities, and record and remind the problems that arise. After the completion of the group's task, each group carries out self-evaluation and evaluation, requiring everyone to participate, and carries out a simple discussion to form an effective record. Finally, selfrating [6]. Teachers provide advice and suggestions on the mission procedures and organizational efficiency, team work and challenges. In order to encourage advancement, teachers can make encouraging group ranking and exchange suggestions with the group so as to achieve consensus and provide experience for the next development.

Teachers should understand the curriculum content of tourism specialty. The specialty of tourism English determines that it breaks through the traditional pure task management mode of cooperative teaching in cooperative teaching. Students need to perform situational role-playing function. Therefore, teachers' understanding of tourism professional knowledge will determine the organizational effect of cooperative teaching to a considerable extent.

Teachers should control their own roles. In cooperative teaching, teachers' participation opportunities, roles and speech expression will have an impact on the development of learning process. Teachers as a whole are the organizers, task-givers and process supervisors of cooperative learning. But in a specific group, they are one of them and cannot impose personal authority or opinions on other members. Therefore, teachers should grasp their personal roles in cooperative teaching.

The choice of educational content must adapt to the development of cooperative education. Teaching content decides the form of teaching, so what teaching means to use is to have a clear understanding and grasp of the content of the textbook and teaching objectives. Classroom-based teaching is suitable for classroom teaching and collective teaching. In the teaching, when using teaching methods, the leading role of content should not be deliberately ignored.

Focus on training students' self-learning ability. The implementation of any learning method is for the purpose of improving academic performance and comprehensive ability. It benefits from the cooperation and practice of students. Cooperative learning is an effective means to improve students self-control quality. In the process of learning, students are also encouraged to actively develop their personal skills and avoid hitchhiking.

Avoid the formalization of cooperative teaching. The basis of implementing cooperative learning mode is to improve education level and meet the needs of high quality education. The cooperative teaching of tourism English also meets the needs of the society. Therefore, we must ensure the practical effect of cooperative teaching rather than cooperative teaching in tourism English curriculum for the sake of popularity or coping form, so as to realize the high-level training of tourism talents.

It is important to ensure that the incentives are used in the curriculum development. The effective use of incentives in teaching is essential, especially in cooperative learning. From the psychological point of view, individuals are eager to be concerned, hope that the progress achieved is recognized and the individual needs are recognized by all. Therefore, in the process of practical cooperative learning, teachers should always pay attention to the progress and efforts made by each student, and give incentives such as oral or small gifts as appropriate. Thus, students can see that the teacher is concerned about their own progress. On the other hand, it can enhance students' self-confidence and sense of honor.

\section{ESTABLISHMENT OF EVALUATION SYSTEM FOR TOURISM ENGLISH COOPERATIVE LEARNING}

\section{A. Guiding Ideology}

The traditional learning assessment is based on the results. This situation will be changed by cooperative learning in tourism English. The test and requirement for students in modern society are all-round. Quality education has become the mainstream of talent cultivation. This is also the original intention of introducing and implementing cooperative learning mode into our tourism English curriculum. Therefore, the evaluation of cooperative learning effect of tourism English will focus more on hierarchy and objectives, and the participants will not only be limited to students, but also including teachers and others [7]. The final evaluation of the classroom is more reasonable and scientific, and promotes the dissemination and use of cooperative learning methods.

The subject of evaluation refers to who will participate in the course evaluation and what conditions or requirements the participants should have. Subject setting is based on the understanding of cooperative teaching and professional courses or practice, or has certain authority in a certain field. In this sense, on the one hand, the main body of evaluation is the textbook professionals, other relevant professional teachers, students, teaching managers. The subject of evaluation refers to who will participate in the course evaluation and what 
conditions or requirements the participants should have. Subject setting is based on the understanding of cooperative teaching and professional courses or practice, or has certain authority in a certain field. In this sense, on the one hand, the main body of evaluation is the textbook professionals, other relevant professional teachers, students, teaching managers, on the other hand, it can also be enterprise personnel, such as travel agency managers, hotel managers or related industry personnel, or authoritative third institutions and other personnel. For the evaluation subjects of tourism English cooperative teaching, the personnel department or the managers of relevant departments of foreign-related tourism hotels are more professional and closer to social practice. After all, learning is for application, practice is the standard to test everything.

\section{B. Evaluation System of Teachers' Teaching Process}

The evaluation of tourism English cooperative learning is divided into two parts: the teacher curriculum evaluation system and the student ability evaluation system. It measures the effect of teacher-and- student cooperative education.

\section{1) Explanation of system construction}

The evaluation system of teacher's teaching process is based on whether tourism English teachers can understand the theory and application of cooperative learning. It gets rid of the traditional curriculum which focuses on teaching style, blackboard writing, teaching methods, assignment and analysis, but reflects students' autonomy, gives full play to students' subjective behavior. Teachers play the role of organization, coordination, management and assessment. Therefore, the evaluation points, contents and scores of the evaluation system focus on the consideration of the relevant links of cooperative teaching, which is more specific and detailed. This evaluation index can help teachers better understand the content of cooperative learning and provide guidance for students. It reflects teachers' high level of participation in the curriculum design. This is a major challenge for teachers. At the same time, the construction of the system also breaks down the evaluation of the teaching effect, and emphasizes the management role of teachers in the process of cooperative learning. The teaching effect has the construction of students' academic evaluation system, which also conforms to the law of education. Students' own progress can better illustrate the teaching results, and also fundamentally reflect the problems existing in the teaching process [8]. Therefore, there is room for further improvement.

\section{2) Evaluation implementation}

The assessment of learning process in cooperation with teachers is usually the assessment of achievement. The evaluation method is the comprehensive evaluation method of spot-checking courseware, attending classes, interviewing teachers and students, and the final evaluation results are based on the cumulative scores. The combination of self-evaluation and evaluation is adopted to reflect the difference of teaching process. In view of the fact that most of the courses for tourism English majors take semester as the teaching cycle, the evaluation of teachers is basically carried out in the middle and the end of the semester, and the average score is the final evaluation result. The total score of more than 80 is a good thing, which means that the teacher is very clear about the implementation of cooperative learning, can use their theory to guide teaching work, and can control the development of its links. More than 70 scores have been allocated, which indicates that teachers need to be strengthened in some areas. However, they have generally understood the theory of cooperative learning and its implementation and development requirements If the total score is below 70, we need to check the deficiencies according to the missing items. It indicates that the mastery and application of knowledge related to cooperative learning is not in place, and we need to explore and improve it.

\section{Evaluation System of Students' Ability}

The evaluation of tourism English cooperative learning is divided into two parts: the teacher curriculum evaluation system and the student ability evaluation system. It measures the effect of teacher-and-student cooperative education.

\section{1) Explanation of system construction}

The construction of students' ability system is mainly based on whether the teaching method of cooperative learning promotes students' progress, whether it meets the training objectives and expectations, and whether students agree with cooperative learning and cooperate actively in the whole learning process. According to the objectives and contents of cooperative learning, the evaluation of students is carried out from three aspects: basic literacy, knowledge application ability and ability cultivation. It will specifically evaluate comprehensive indicators such as daily learning and management, knowledge application, organizational ability, management ability, innovation ability and so on, so as to get rid of passing the examination as a single consequential act of assessing test results directly in the past. The starting point of setting the evaluation index is to improve students' comprehensive ability and carry out the training goal of "student-centered".

\section{2) Evaluation implementation}

To evaluate students, process evaluation is generally adopted, focusing on the changes and achievements of students in the whole learning process as well as shortcomings. In order to maintain the overall fairness of the evaluation, the weekly average of the evaluation is acceptable, and the normal classroom performance of students is included in the evaluation scope. The total score above 80 points is excellent, which shows that students can adapt to the development of cooperative learning and can show themselves in it. Cooperative learning improves the overall quality and skills of students. The total score above 60 points is the basic cooperation, which indicates that students have not fully adapted to the teaching mode of cooperative learning, and have not yet developed themselves and required themselves in this environment, but basically agree with the development of this mode. With the increase of cooperation and the continuous guidance of teachers, the overall ability of students will be strengthened. Less than 60 percent indicates that students are not suitable for the teaching mode of cooperative learning at all, and have not recognized the effectiveness of the mode of cooperative learning from the heart. The total score is less than 60 , which indicates that the students have not adapted to the cooperative learning teaching mode at all, and have not recognized the effectiveness of the cooperative learning mode from the heart. This type of students need to raise awareness, 
maintain communication with teachers and other students as soon as possible, and change their learning concepts [9]. Of course, teachers should pay close attention to such students and guide them correctly so that they can adapt to the teaching mode as soon as possible, so as to improve their abilities and achievements in an all-round way.

\section{Assessment Feedback Mechanism}

Any assessment and evaluation criteria are set based on a certain purpose and within a certain range. Therefore, different assessment criteria for the same content of the assessment results tend to appear larger deviations. Based on this consideration, in order to realize the effective implementation of cooperative learning of tourism English better, We must establish a specific feedback system so that we can incorporate representativeness or representativeness into every assessment, so as to improve or promote them later, which is also the inherent requirement of improving the assessment system.

Teachers can be graded either by students or teachers, or by teaching administration teachers. Different people's assessment and judgment and individual situation mastery level are different, which will lead to different assessment results. Therefore, we need to set up a certain feedback system to understand the teachers' corresponding situation and personal views in cooperative learning classroom. The feedback system mainly covers five parts: the overall evaluation of teaching, self-analysis, feedback to evaluation opinions, self-awareness and the final evaluation results of schools. The function of the feedback system is to help teachers to understand the assessment results comprehensively, on the other hand, to help schools to understand teachers' teaching status and teaching ideas comprehensively, and ultimately to achieve the continuous improvement of teachers' teaching level and the recognition and satisfaction of teaching methods [10]

Students can be mainly assessed by teachers and classmates. there will be some deviation, teachers' evaluation is relatively more objective. Student feedback helps students to understand their performance and problems in cooperative learning. It also helps students find out the crux of some problems. In turn, teachers and students can understand each other and make progress together. At the same time, for teachers, it is helpful to understand the students' learning state, characteristics and ideas in an all-round way. Therefore, they arrange their next roles and teaching according to their abilities.

\section{CONCLUSION}

For tourism English, cooperative learning is of great significance. The need for talents in the new era is not only the so-called "good study" and "good achievement", but also a compound talent with strong comprehensive ability and high basic quality. Cooperative learning opens up new prospects for educational reform. It has an important influence on transforming the main body of teaching, mobilizing students' initiative and innovation in learning, and cultivating students' comprehensive ability. Cooperative learning is the direction and mainstream of educational reform. However, cooperative learning is only one of the teaching modes, and it is not omnipotent, and the effect is not the same or applicable to the teaching of various subjects. Various teaching subjects should adopt different teaching modes or strategies, or a combination of multiple strategies, according to their own characteristics and teaching purposes, in order to improve the teaching effect. At present, we still have some exploratory research on cooperative teaching. Cooperative learning itself involves many contents and links, and its theoretical basis is constantly improving and developing. We should look at the cooperative teaching model as a whole in order to maximize its use-value and achieve double-winning effect between students and teachers.

\section{REFERENCES}

[1] J. O. Brown, The Elements of Language Curriculum: Systematic Approach to Program Development, Heinle \& HeinlePubishers,1995.

[2] D. Pratt, Curriculum Design and Development, Harcourt Brace Jovanovich, Inc., 1980.

[3] T. Wang, Introduction to Cooperative Learning, Educational Science Press, 1994

[4] T. Wang, Cooperative Learning: Principles and Strategies, Beijing: Xueyuan Publishing House, 2001.

[5] Y. J. Tang, Research on the Theory and Practice of Modern Foreign Language Teaching, Beijing: Xueyuan Publishing House,2001.

[6] M. H. Qian, Research on Vocational Education and Social Development, Harbin: Heilongjiang Education Press, 1999.

[7] Y. Fan, English Learning Method, Shanghai: Shanghai Foreign Language Education Press, 2002.

[8] J. Guo, The Application of Native Meaning Activities in English Teaching, Beijing: Capital Normal University Press,2005.

[9] Q. Xu, "Research on the Application of Cooperative Teaching Model in Outdoor Sports Courses in Colleges and Universities," Science and Wealth, No. 10, October 2014.

[10] D. F. Xiang, "Brief discussion on group management and construction strategy,” Quality Education Forum, No. 6, June 2017. 